\title{
Impact of radiation on hygrothermal behavior of ventilated cavity wall
}

\author{
Thibaut Colinart ${ }^{1, *}$, Mathieu Bendouma ${ }^{1}$, and Patrick Glouannec ${ }^{1}$ \\ ${ }^{1}$ Univ. Bretagne Sud, UMR CNRS 6027, IRDL, F-56100 Lorient, France
}

\begin{abstract}
This work deals with the performance of a high school building renovated with prefabricated ventilated façade elements through a field experimental study under oceanic climate. Temperature, relative humidity and heat flux were measured at different points of the renovated façade and are analyzed as function of the exterior boundary conditions. The measured data are compared to numerical results. For this purpose, two models are considered: an energy balance is made for the cladding, while a heat and moisture transfer model is solved within the insulation materials. In this study, particular attention is paid in the influence of the radiative exchanges in short and long wavelengths on the hygrothermal behavior of the retrofitted wall.
\end{abstract}

\section{Introduction}

Prefabricated ventilated façade elements are increasingly used for upgrading the thermal insulation of the building envelope and for reducing energy consumption. However, the implications of using ventilated façades are less straightforward in terms of moisture control $[1,2]$. Behind the large number of experimental studies, numerous works aim to predict the hygrothermal behavior of cavity walls. Most of them used WUFI software, in which a simplified model for cavity wall ventilation is implemented [3], and discussed for instance the influence of constant or varied air change rate $\mathrm{ACH}$ on the simulation [4].

Nevertheless, a cavity wall combines other physical phenomenon that may influence hygrothermal behavior. For instance, short-wave radiation (e.g. solar radiation) plays an important role in the thermal balance of cladding and cavity, but also in the ventilation of air cavity [5]. WUFI requires at least two irradiances among global horizontal irradiance (GHI), diffuse horizontal irradiance (DHI) or direct normal irradiance (DNI). If only GHI is available, a decomposition model $k d$ should be used to get DHI. As mentioned in [6], decomposition models can range from very simple formulations (Reindl, Erb, Ohm...) to more elaborate expressions (DISC, DIRINT...). Then, irradiance has to be converted into the plane of array. While the conversion of DNI is purely geometrical, it exists several transposition models $R d$ to convert DHI [7], ranging from the simple isotropic model (as in WUFI [8]) to more complex models (e.g. Reindl or Perez model).

Next, long-wave radiation is the second relevant phenomenon. It includes the thermal radiation exchange between the exterior surface and the surroundings surface (ground,

* Corresponding author: thibaut.colinart@univ-ubs.fr 
other buildings, sky). Radiation balance requires the knowledge of all temperatures, surfaces and view factors. In addition, as temperature is expressed with a fourth power, radiation balance is often linearized and combined with convective heat transfer. This is done basically in WUFI. However, such simplification is not relevant when investigating building surface undercooling due to night radiation [9]. Therefore, WUFI proposes to use "Explicit Radiation Balance" option. In the presence case, ground (and implicitly other building) surface temperature is set to air temperature, which is a common and wellaccepted assumption [10]. Different models exist for the calculation of sky temperatures: the simplest need only air temperature while more elaborated models require advanced inputs like cloud cover. Recently, Evangelisti et al. [11] reviewed existing correlations of sky temperature and noted that differences up to $20^{\circ} \mathrm{C}$ can be observed between models.

The influence of shortwave and/or longwave radiations models on building global performance has been already previously investigated [11-13]. In this work, we aim to evaluate their influence more specifically on the hygrothermal behavior of ventilated façade and to compare numerical results to experimental data.

\section{Presentation of the case study}

The case study concerns a high school building renovated with prefabricated ventilated façade elements [14]. Fig. 1 gives an overview of the design of these elements and of their application on the existing building envelope. One South-East oriented element was instrumented with thermocouples and capacitive humidity sensors (see Fig. 1) over two years. Local weather data were measured by a weather station located on the roof of nearby building. In addition, pyranometer was used occasionally to assess solar radiation on the vertical façade.
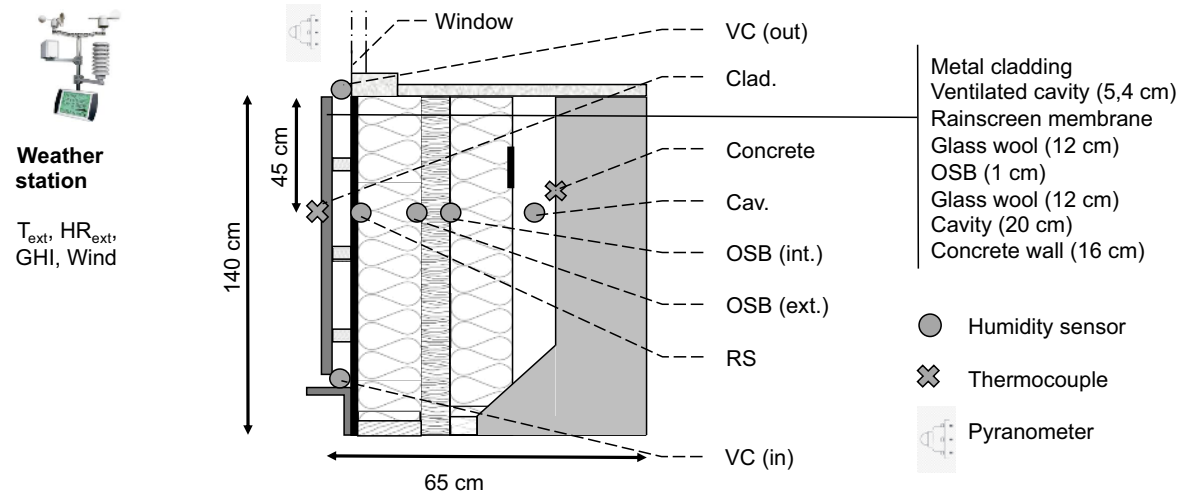

Fig. 1. Overview of the design and the instrumentation of the prefabricated ventilated façade element.

Equations describing heat and moisture transfer within one element are described hereafter. Since metal cladding is thin (less than $2 \mathrm{~mm}$ ), highly conductive, air- and moisture-tight, a single temperature representative of the cladding is calculated from the heat balance:

$$
\alpha_{\text {clad }}^{S W} I_{\text {clad }}^{S W}+q_{L W}^{\text {ext }}+q_{L W}^{V C}+h_{\text {conv }}^{\text {ext }}\left(T_{\text {ext }}-T_{\text {clad }}\right)+h_{\text {conv }}^{V C}\left(T_{V C}-T_{\text {clad }}\right)=0
$$

Convective heat transfer coefficients $h_{\text {conv }}^{V C}$ and $h_{\text {conv }}^{\text {ext }}$ are respectively assumed constant and equal to $5 \mathrm{~W} \cdot \mathrm{m}^{-2} \cdot \mathrm{K}^{-1}$ within the ventilated cavity (according to ISO 6946) and a 
function of wind velocity at the exterior surface (according to WUFI). Longwave radiation is explicitly expressed in the ventilated cavity as:

$$
q_{L W}^{V C}=\frac{\sigma\left(T_{R S}^{4}-T_{\text {clad }}^{4}\right)}{\frac{1-\varepsilon_{R S}^{L W}}{\varepsilon_{R S}^{L W}}+\frac{1}{F_{R S-c l a d}}+\frac{\left(1-\varepsilon_{\text {clad }}^{L W}\right)}{\varepsilon_{\text {clad }}^{L W}}}
$$

Longwave radiative heat exchange with the sky and the local environment (ground + other buildings) writes:

$$
q_{L W}^{\text {ext }}=\varepsilon_{\text {clad }}^{L W} \sigma\left(F_{\text {sky-clad }}\left(T_{\text {sky }}^{4}-T_{\text {clad }}^{4}\right)+\left(1-F_{\text {sky-clad }}\right)\left(T_{\text {ext }}^{4}-T_{\text {clad }}^{4}\right)\right)
$$

In Eq. (3), local environment temperature is set to measured exterior temperature. In a first approximation, sky view factor $F_{\text {sky-clad }}$ is set to 0.5 according to ISO 52017. Three approaches are tested for the sky temperature: 1. an average difference of $11{ }^{\circ} \mathrm{C}$ is set between $T_{\text {ext }}$ and $T_{\text {sky }}$ (ISO 52017), 2. the equation from Martin and Berdahl for cloudy sky and 3. the equation used in WUFI. Note that the two last equations require the knowledge of cloud cover. Here, an average value of 6 okta (corresponding to a cloud index of $75 \%$ ) is used.

Last, shortwave irradiance $I_{\text {clad }}^{S W}$ is evaluated from measured GHI using decomposition and transposition models. Here, two approaches are tested: a simple one (decomposition model $k d=$ Reindl model, transposition model $R d=$ isotropic model) and an advanced one (decomposition model $k d=$ DISC model, transposition model $R d=$ Reindl model).

Averaged temperature and relative humidity within the ventilated cavity are evaluated by solving the following energy and mass balances:

$$
\begin{gathered}
\mathrm{V} \frac{d h_{V C}}{d t}=q_{\text {conv }}^{V C} \mathrm{~S}+q_{\text {conv }}^{\text {wall }} \mathrm{S}+\frac{A C H V}{3600} \rho c_{p, \text { air }}\left(T_{\text {ext }}-T_{V C}\right) \\
\frac{d m_{v, V C}}{d t}=q_{m}^{\text {wall }} S+\frac{A C H V}{3600}\left(\rho_{v, \text { ext }}-\rho_{v, V C}\right)
\end{gathered}
$$

Air change rate $\mathrm{ACH}$ is assumed constant and equal $600 \mathrm{~h}^{-1}$. Convective moisture transfer coefficient is deduced from convective heat transfer coefficient through Lewis relation.

Heat and moisture transfer equations are solved within porous hygroscopic materials [15]. Note that the rainscreen membrane is considered as a resistive layer. At the interface facing the existing wall, convection, longwave radiation and latent heat transfer are considered.

Initial conditions are extrapolated from measurements. Last, all equations are implanted and solved in Comsol Multiphysics.

\section{Results and discussion}

Simulations are performed for 10 days of October and results presented hereafter focus on two consecutive days, a sunny one and a cloudy one. Fig. 2a compare the measured shortwave irradiation measured on the vertical wall with the calculated ones: on sunny day, differences up to $150 \mathrm{~W} \cdot \mathrm{m}^{-2}$ and a light delay of maximal irradiation are observed with the simple conversion approach, while a good agreement is found for the advanced conversion approach; on cloudy day, absolute (resp. relative) errors less than $10 \mathrm{~W} \cdot \mathrm{m}^{-2}$ (resp. $10 \%$ ) are observed for both conversion approaches. Fig. $2 b$ compare the different calculated sky temperatures with the exterior air temperature and dew point. Sky temperature calculated according to ISO 52017 presents the lowest values since it corresponds to a clear sky model. Models for cloudy sky behaves differently: WUFI model presents similar variations 
as dew point whereas Martin and Berdahl model follows exterior air temperature variations. However, differences between both models do not exceed $5{ }^{\circ} \mathrm{C}$ during daytime and $1.5{ }^{\circ} \mathrm{C}$ during nighttime.

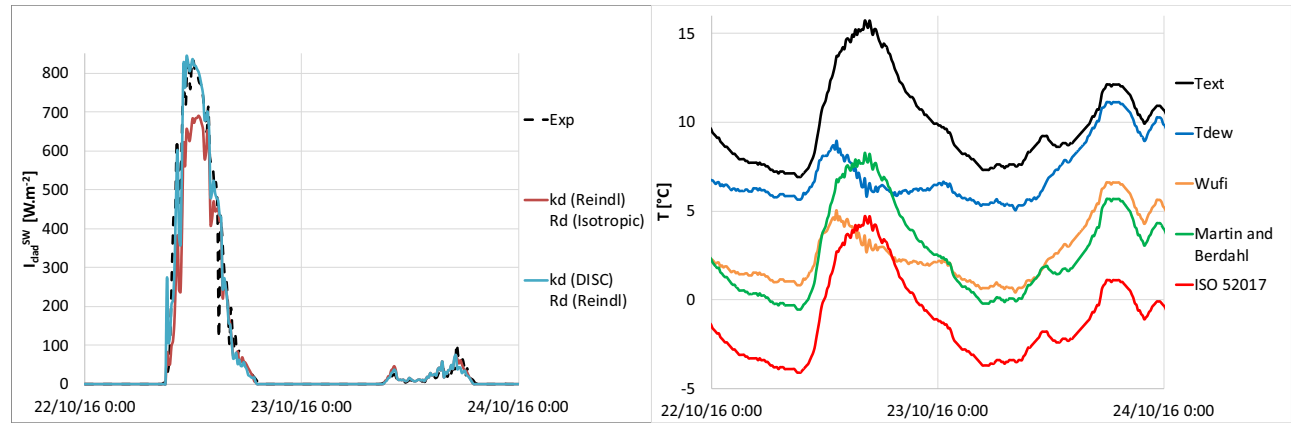

Fig. 2. Measured and calculated shortwave irradiance (a); measured exterior air temperature and dew point and calculated sky temperatures (b).

Measured and simulated temperatures and relative humidity are presented in Fig. 3. Reference simulation is run with advanced conversion approach for shortwave irradiation and with Martin and Berdahl model for sky temperature. Other simulations are obtained changing parameter one at a time. In addition, root mean square errors (RMSE) against the reference simulation are calculated in Table 1 for day- and nighttime. At first glance, all simulations have the same dynamic as the measured data, except close to the OSB board. At this point, the peaks of relative humidity are delayed of approx. 1 hour: chosen material hygrothermal properties induce a small thermal and hygric inertia. On the other hand, amplitude differences exist between the reference simulation and experimental data: during daytime, temperature is generally overestimated and relative humidity is underestimated; the opposite occurs during nighttime. RMSE during daytime are higher which underlines the high importance of solar radiation on hygrothermal behavior. Also, RMSE is lower deeper within the prefabricated element (i.e. close to the OSB board).

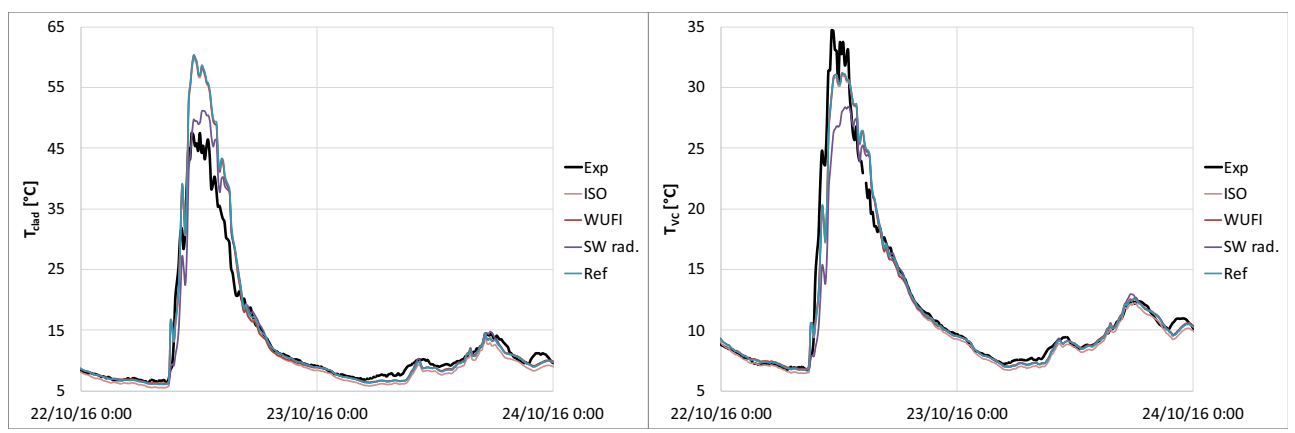




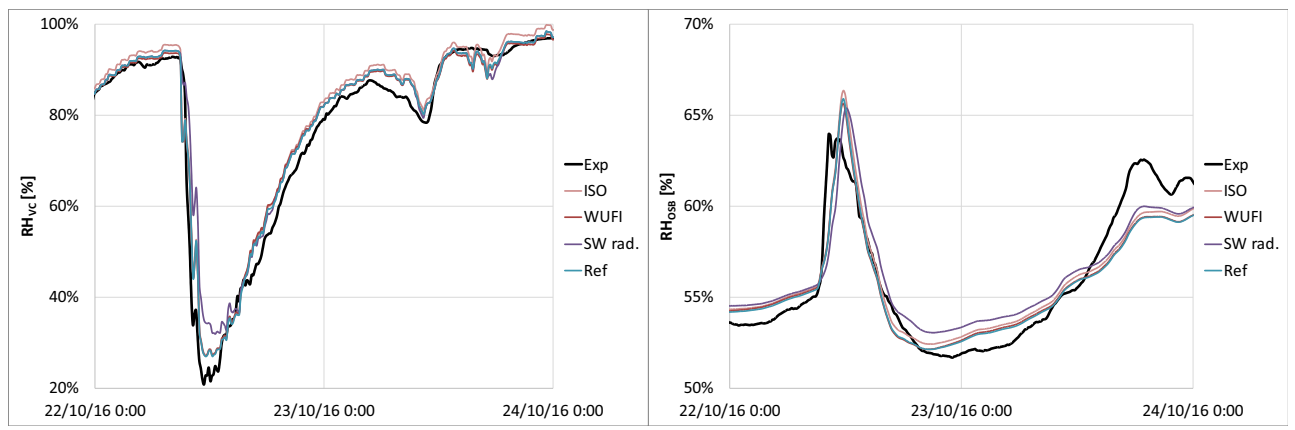

Fig. 3. Measured and simulated temperatures of cladding and ventilated cavity (top) and measured and simulated relative humidity of ventilated cavity and OSB (bottom).

Obviously, shortwave irradiation calculation approach has a great influence during daytime of sunny day: differences up to $12{ }^{\circ} \mathrm{C}$ can be observed for cladding temperature or up to $14 \%$ for ventilated cavity relative humidity. These differences propagate toward the rest of wall, but to a lower extend. During nighttime, no differences are noted around the ventilated cavity, but a small error is observed close to OSB board although thermal and hygric inertia are small for this prefabricated element. Nevertheless, RMSE do exceed 0.6 $\%$ which is less than usual sensor accuracy.

Regarding sky temperature, differences observed between the cloudy sky temperature models (WUFI and Martin and Berdahl) are rather limited all day long. On the other hand, clear sky temperature model (ISO 52017) gives larger differences with the reference simulation but also with experimental data. This is particularly true during nighttime. Since sky temperature is lower, undercooling phenomenon is enhanced and ventilated cavity temperature is found to reach occasionally dew point: condensation may occur either on the cladding or on the rainscreen membrane. Consequently, cloudy sky temperature model seems to give better results even if cloud cover index is not always available. In the rest of the wall, its influence is however rather limited.

Table 1. Root mean square errors (in ${ }^{\circ} \mathrm{C}$ or $\%$ ) calculated for day- and nighttime.

\begin{tabular}{|c|c|c|c|c|c|c|c|c|}
\hline & \multicolumn{4}{|c|}{ Daytime } & \multicolumn{4}{c|}{ Nighttime } \\
\hline & $\mathrm{T}_{\text {clad }}$ & $\mathrm{T}_{\mathrm{VC}}$ & $\mathrm{HR}_{\mathrm{VC}}$ & $\mathrm{HR}_{\mathrm{OSB}}$ & $\mathrm{T}_{\text {clad }}$ & $\mathrm{T}_{\mathrm{VC}}$ & $\mathrm{HR}_{\mathrm{VC}}$ & $\mathrm{HR}_{\mathrm{OSB}}$ \\
\hline $\mathrm{Exp}$ & 5.30 & 2.90 & 5.7 & 1.7 & 0.66 & 0.31 & 2.3 & 1.1 \\
\hline $\mathrm{SW} \mathrm{rad}$ & 3.91 & 1.65 & 4.2 & 1.1 & 0 & 0 & 0 & 0.6 \\
\hline $\begin{array}{c}\mathrm{T}_{\text {sky }} \\
(\text { WUFI })\end{array}$ & 0.33 & 0.13 & 0.5 & 0.1 & 0.18 & 0.07 & 0.4 & 0.1 \\
\hline $\mathrm{T}_{\text {sky }}$ (ISO) & 0.56 & 0.23 & 1 & 0.3 & 0.56 & 0.23 & 1.2 & 0.2 \\
\hline
\end{tabular}

\section{Conclusions}

This work focused on the modeling of hygrothermal behavior of ventilated cavity wall. Special attention is paid on the influence of short- and longwave radiation during the comparison with experimental data. First, we underlined that global horizontal irradiance $G H I$ have to be converted to the plane of array using conversion models. Here, we found 
that advanced conversion model fitted better measured irradiance. In addition, significant differences are observed between simple and advanced approaches, especially during daytime for cladding and ventilated cavity temperatures. Second, we evaluated three sky temperature models: clear sky temperature model tended to enhance undercooling phenomenon, leading thus to the prediction of condensation within the ventilated cavity; on the other hand, cloudy sky temperature models gave better results compared to experimental data, in spite that only mean cloud cover index has been used. Further works consist in confirming the present findings for other periods (summer and winter) and in comparing the above-mentioned sensitivity to the ones of other parameters (external and cavity heat transfer coefficient and air change rate within the ventilated cavity).

\section{References}

1. M. Salonvarra, A.N. Karagiozis, M. Pazera, W. Miller, In Thermal Performance of the Exterior Envelopes of Whole Buildings Tenth International Conference (2007).

2. J. Straube, G. Finch, Building Science Corporation, 1-25 (2009).

3. A.N. Karagiozis, H.M. Künzel, J. ASTM Int., 6, 1 (2009).

4. O. Hägerstedt, L.E. Harderup, In Proceedings of the 9th Nordic Symposium on Building Physics (2011).

5. J. Langmans, S. Roels, Build. Environ., 87, 177 (2015).

6. C. Bertrand, G. Vanderveken, M. Journée, Renewable energy, 74, 618 (2015).

7. C.A. Gueymard, J.A. Ruiz-Arias, Sol. Energy, 128, 1 (2016).

8. K. Sedlbauer, M. Krus, C. Fitz, H.M. Künzel, In XII DBMC international conference on durability of building materials and components (2011).

9. E. Barreira, J.M.P.Q. Delgado, N.M.M. Ramos, V.P. de Freitas, J. Build. Perform. Simul., 6, 337 (2013).

10. H. Janssen, J. Carmeliet, H. Hens, Build. Environ., 39, 825 (2004).

11. L. Evangelisti, C. Guattari, F. Asdrubali, Energy Build., 183, 607 (2019).

12. P.G. Loutzenhiser, H. Manz, C. Felsmann, P.A. Strachan, T. Frank, G.M. Maxwell, Sol. Energy, 81, 254 (2007).

13. F. Hemmatia, F. Tariku, In Proceedings of the 7th International Building Physics Conference (2018).

14. T. Colinart, M. Bendouma, P. Glouannec, Energy Build, 186, 221 (2019).

15. D. Lelievre, T. Colinart, P. Glouannec, Energy Build., 84, 617 (2014). 